\title{
Identification of Korean Ginseng (Panax ginseng) Cultivars Using Simple Sequence Repeat Markers
}

\author{
Yurry Um ${ }^{1}$, Mei-Lan Jin ${ }^{1}$, Ok-Tae Kim ${ }^{1}$, Young-Chang Kim ${ }^{1}$, Seong-Cheol Kim ${ }^{1}$, Seon-Woo Cha ${ }^{1}$, Ki-Wha Chung ${ }^{2}$, \\ Serim Kim³, Chan-Moon Chung ${ }^{3}$, Yi Lee ${ }^{3}$ * \\ ${ }^{1}$ Department of Herbal Crop Research, National Institute of Horticultural and Herbal Science, Rural Development Administration, \\ Eumseong 27709, Korea \\ ${ }^{2}$ Department of Biological Science, Kongju National University, Gongju 32588, Korea \\ ${ }^{3}$ Department of Industrial Plant Science and Technology, Chungbuk National University, Cheongju 28644, Korea
}

\begin{abstract}
Panax ginseng has been one of the most important herbal medicines used in Eastern Asia. Recently, various molecular markers have been developed to authenticate Panax species, but these markers cannot differentiate the exact varieties or variants of Korean ginseng cultivars. In this study, six cultivars of Korean ginseng (Chunpoong, Yunpoong, Gopoong, Gumpoong, Jakyung, and Hwangsook), $P$. quinquefolius, and $P$. notoginseng were differentiated by simple sequence repeat (SSR) marker development. Specific primer sets were designed for the 54 candidate sequences containing SSRs that were predicted. Finally, eight polymorphic SSR loci were developed. DNA fragment analysis was performed using fluorescence-labelled primers for the amplicons. Reproducibility tests were carried out using multiple samples of Korean ginseng cultivars and Panax species. Eight primer sets (PgSSR07, PgSSR08, PgSSR09, PgSSR17, PgSSR37, PgSSR40, PgSSR51, and PgSSR53) showing polymorphism were used for phylogenetic relationship analysis. Consequently, six Korean ginseng cultivars (Chunpoong, Yunpoong, Gopoong, Gumpoong, Jakyung, and Hwangsook), $P$. quinquefolius, and $P$. notoginseng could be identified using the combination of SSR markers discovered.
\end{abstract}

Keywords Panax, Korean ginseng cultivars, SSR markers, DNA fragment analysis, Phylogenetic relationship

\section{INTRODUCTION}

Korean ginseng (Panax ginseng, C.A. Meyer) is an herbaceous perennial plant of the genus Panax (Araliaceae). Korean ginseng is a plant that grows only in the Far East areas, as in Asia, China, Manchuria, and Russia (Woo et al. 2004). The main physiologically active components of ginseng are saponins, phenols, polyacetylenes, alkaloids, and polysaccharides (Lee et al. 2008). These components act on the central nervous, cardiovascular, endocrine, and immune systems, and are recently reported to have antioxidant and anti-stress effects (Nam et al. 2005).

In general, the Panax genus is divided into nine species: $P$. ginseng, $P$. notoginseng, $P$. quinquefolius, $P$. japonicus, $P$. pseudoginseng, $P$. assamicus, $P$. sokpayensis, $P$. sikkimensis, and P. bipinnatifidus (Sharma and Pandit
2009). However, the number of Panax species is unclear because several scholars define the same species differently. Many studies identify plants species and varieties using morphological, cytological, anatomical, physiological, and ecological methods (Woo et al. 2004; Yu et al. 2009; Jee et al. 2014; Bai et al. 2015; Kim et al. 2015). Using such morphological characteristics to distinguish among varieties can lead to confusion because expression may be the result of a combination of genetics and environment (Jo et al. 2013). Furthermore, molecular techniques have added another level of classification through study of DNA (Lim and Choi 1990; Lim et al. 1993; Hon et al. 2003). In order to identify the plant species, restriction fragment length polymorphism (RFLP), random amplified polymorphic DNAs (RAPD), amplified fragment length polymorphism (AFLP), and simple sequence repeat (SSR) were used

Received January 26, 2016; Revised January 26, 2016; Accepted January 28, 2016; Published February 28, 2016

*Comesponding author Yi Lee, leeyi22@cbnu.ac.kr, Tel: +82-43-261-3373, Fax: +82-43-261-3373 
(Powell et al. 1996). SSR markers, or microsatellites, are abundantly dispersed within the genome and have been widely used as genetic markers. SSR markers are very useful for a spectrum of genetic and breeding applications because of their reproducibility, co-dominant inheritance, multi-allelic nature, and genome coverage (Powell et al. 1996; Kim et al. 2007; Silva et al. 2013).

Recently, researchers reported the development of ginseng SSR markers and genetic analysis among national collection species (Park et al. 2009), genetic diversity analysis between wood-cultivated ginseng and fieldcultivated ginseng (Jo et al. 2009), as well as identification of P. ginseng and P. notoginseng (Ahn et al. 2009). Besides, many researchers have tried to identify ginseng species and varieties using SSR markers (Kim et al. 2007; Ma et al. 2007; Nguyen et al. 2010; Bang et al. 2011a, 2011b). SSR markers are important for several types of research, including the assessment of genetic diversity, development of genetic maps, comparative genomics, marker-assisted selection, and other plant breeding fields. However, there are few studies on genetic polymorphism analyses of domestic cultivars using SSR markers. These studies were inconclusive because the ginseng genome is very large (3.12 billion base pairs) and there are many recently developed varieties. Therefore, the development of more markers is necessary for molecular breeding and variety identification.

The aim of this research was to develop SSR markers from Korean ginseng cultivars and differentiate the $P$. ginseng cultivars and Panax species. The SSR markers were identified from the database which was constructed using an enriched SSR library and the polymorphism of the markers was investigated using DNA fragment analysis.

\section{MATERIALS AND METHODS}

\section{Plant materials and DNA extraction}

This study was carried out with 115 Panax accessions grown in Korea. Panax samples used in this study were Korean ginseng cultivars (17 Chunpoong, 22 Yunpoong, 15 Gopoong, 10 Gumpoong, 23 Jakyung, and 20 Hwangsook) collected from various local fields in Goesan and Suwon,
Table 1. Source of the Panax species and Panax ginseng cultivars used in this study.

\begin{tabular}{lllc}
\hline \multicolumn{1}{c}{ Species } & \multicolumn{1}{c}{ Cultivar } & Accession & $\begin{array}{c}\text { No. of } \\
\text { sample }\end{array}$ \\
\hline P. ginseng & Chunpoong & KT\&G & 17 \\
& Yunpoong & KT\&G & 22 \\
& Gopoong & Local & 15 \\
& Gumpoong & Local & 10 \\
& Jakyungjong & KT\&G & 23 \\
& Hwangsookjong & Local & 20 \\
$P$. quinquefolius & & NIHHS & 5 \\
$P$. notoginseng & & NIHHS & 3 \\
\hline
\end{tabular}

${ }^{2)}$ KT\&G: name of a Korean ginseng corporation, NIHHS: National Institute of Horticultural and Herbal Science.

Korea. Moreover, 5 P. quinquefolius and 3 P. notoginseng were obtained from KT\&G cooperation company (Daejeon, Korea) and National Institute of Horticultural and Herbal Science (Eumseong, Korea), respectively (Table 1). One hundred $\mathrm{mg}$ of fresh leaves were used for genomic DNA extraction using TissueLyser (Qiagen, Düsseldorf, Germany) and the DNeasy plant DNA isolation kit (Qiagen GmbH, Hilden, Germany).

\section{SSR detection and specific primer design}

A total of 3,773 DNA sequences of $P$. ginseng were collected through downloading of 2,549 genome survey sequences from the National Center for Biotechnology Information (NCBI) database and 1,224 microsatelliteenriched library (MEL) sequences from the data collected by Kim et al. (2007). Putative Panax MEL sequences were analyzed by the SSR identification tool (http://www. gramene.org/db/markers/ssrtool) program. Primer pairs flanking the SSRs were designed using the Primer3 program (Koressaar and Remm, 2007; Untergrasser et al. 2012) with a length of 18 to $25 \mathrm{bp}$, amplification product size of 100 to $500 \mathrm{bp}$, annealing temperature $(\mathrm{Tm})$ ranging from $54^{\circ} \mathrm{C}$ to $60^{\circ} \mathrm{C}$, and $\mathrm{GC}$ content between $40 \%$ and $60 \%$.

\section{Polymerase chain reaction (PCR) amplification and data analysis}

Twenty $\mu \mathrm{l}$ of PCR mixture contained 10 pmole primers (fluorescence-labeled primer), $10 \mathrm{ng}$ of genomic DNA, 0.1 $\mathrm{mM}$ dNTP, 0.2 units Taq DNA polymerase (RBC 
Bioscience, New Taipei City, Taiwan) and 10× Taq polymerase buffer using a T-gradient Thermoblock PCR system (Biometra, Göttingen, Germany) for 35 cycles. The initial cycle was pre-denaturation for 5 minutes at $94^{\circ} \mathrm{C}$, denaturation for 30 seconds at $94^{\circ} \mathrm{C}$, annealing for 1 minute at $59^{\circ} \mathrm{C}$, and extension for 1 minute at $72^{\circ} \mathrm{C}$ (for the final cycle, 5 minutes added). Electrophoresis was performed using a $10 \%$ polyacrylamide gel. Polymorphic bands were visualized by gel staining using Gelstar (Lonza Inc., Rockland, ME, USA) and photographed under UV Transilluminator (CoreBio System Co., Seoul, Korea). Polymorphic amplicons visualized on polyacrylamide gels were separated in agarose gel electrophoresis. To verify the accuracy of ginseng SSR polymorphisms, the forward primer was labeled and tested on 6 Korean ginseng cultivars, $P$. quinquefolius and $P$. notoginseng. DNA fragment profile data were demonstrated by the SSR markers PgSSR08 and PgSSR51 using NED-labelled primers; PgSSR09 and PgSSR37 using FAM-labelled primers; PgSSR07 and PgSSR40 using VIC-labelled primers; and PgSSR17 and PgSSR53 using PET-labelled primers. Then, we preformed capillary electrophoresis using an ABI3730xl DNA analyzer with GeneScan-500LIZ size standard (Applied Biosystems, Foster City, CA, USA). Based on the resulting data, allele sizes were measured in terms of the numbers of alleles, gene diversity, and polymorphic information content (PIC), using PowerMarker software ver. 3.23 (Liu and Muse 2005). Coefficients of genetic similarity for the eight species used in this study were calculated using the SIMQUAL program

Table 2. Frequencies of microsatellite repeat types in the Panax ginseng sequence collections.

\begin{tabular}{lc}
\hline \multicolumn{1}{c}{ Repeat type } & Simple sequence repeat \\
\hline Di-nucleotide & $8,279(60.1)$ \\
Tri-nucleotide & $3,832(27.8)$ \\
Tetra-nucleotide & $1,070(7.8)$ \\
Penta-nucleotide & $371(2.7)$ \\
Hexa-nucleotide & $153(1.1)$ \\
Hepta-nucleotide & $48(0.3)$ \\
Octa-nucleotide & $16(0.1)$ \\
Total & $13,769(100.0)$ \\
\hline
\end{tabular}

Values are presented as number (\%).
(NTSYS-pc, ver. 2.10; Mogea 1999). A neighbor-joining dendrogram was constructed based on a genetic similarity matrix created in the SHAN clustering program from NTSYSpc using the unweighted pair group method with arithmetic mean algorithm.

\section{RESULTS}

\section{Abundance and distribution of SSRs}

A total of 3,773 sequences were collected and used for the finding of SSRs, defined as di- to octa-nucleotide motifs. Thus, 1,283 sequences ( $34 \%$ of the total sequences) contained SSRs and a total of 13,769 in silico SSR markers were identified. The observed frequencies of di-, tri-, tetra-, penta-, hexa-, hepta-, and octa-nucleotide repeats were $60.1 \%(\mathrm{n}=8,279), 27.8 \%(\mathrm{n}=3,832), 7.8 \%(\mathrm{n}=1,070), 2.7 \%$ $(\mathrm{n}=371), 1.1 \%(\mathrm{n}=153), 0.3 \%(\mathrm{n}=48)$, and $0.1 \%(\mathrm{n}=16)$, respectively (Table 2).

Among the dinucleotide repeats, (AT/AT)n and (TA/TA)n were the most abundant repeat motifs and represented $20.0 \%$ and $17.2 \%$ of dinucleotides, respectively. Among the trinucleotide repeats, (ATA/TAT)n and (TAA/TTA)n were most abundant, with each accounting

Table 3. Abundant SSR motives in the Panax ginseng database. Motifs accounting for $4.9 \%$ or more of each repeat type are included*.

\begin{tabular}{lr}
\hline \multicolumn{1}{c}{ Variable } & SSR motif \\
\hline $\mathrm{AC} / \mathrm{GT}$ & $990(12.0)$ \\
$\mathrm{AG} / \mathrm{CT}$ & $1,240(15.0)$ \\
$\mathrm{AT} / \mathrm{AT}$ & $1,655(20.0)$ \\
$\mathrm{CA} / \mathrm{TG}$ & $1,403(16.9)$ \\
$\mathrm{GA} / \mathrm{TC}$ & $1,340(16.2)$ \\
$\mathrm{TA} / \mathrm{TA}$ & $1,428(17.2)$ \\
AGA/TCT & $192(5.0)$ \\
ATA/TAT & $419(10.9)$ \\
TTG/CAA & $215(5.6)$ \\
GAA/TTC & $220(5.7)$ \\
TAA/TTA & $377(9.8)$ \\
TCA/TGA & $189(4.9)$ \\
AAAT/ATTT & $65(6.0)$ \\
TAAA/TTTA & $62(5.7)$ \\
\hline
\end{tabular}

Values are presented as number (\%).

*SSR: simple sequence repeat. 
for approximately $10 \%$ of the trinucleotides. Among the tetranucleotide repeats, (AAAT/ATTT)n and (TAAA/ TTTA)n were most abundant, with each accounting for approximately $6 \%$ of the tetranucleotides (Table 3 ).

\section{Gel electrophoresis of SSR motifs and DNA fragment analysis}

Fifty-four putative SSR markers were validated for polymorphic markers. The allelic structures of the markers were determined from DNA band patterns from Gelstar stained $10 \%$ polyacrylamide gels (data not shown). Finally, eight markers-PgSSR07, PgSSR08, PgSSR09, PgSSR17, PgSSR37, PgSSR40, PgSSR51, and PgSSR53-amplified polymorphic PCR product bands among Korean ginseng cultivars. The products were analyzed using the DNA fragment analysis method.

A total of eight SSR loci showed polymorphism, producing a total of 33 alleles among the eight Panax species. The observed number of alleles ranged from three (PgSSR07, PgSSR09, PgSSR17, PgSSR40, and PgSSR53) to eight (PgSSR51), with an average of 4.13 alleles per locus. The genetic diversity of each locus ranged from 0.13 (PgSSR53) to 0.78 (PgSSR51), with an average of 0.45. In addition, the heterozygosity values ranged from 0.07
(PgSSR53) to 0.59 (PgSSR08 and PgSSR09), with an average of 0.32. PIC values were calculated for each polymorphic marker using the method of Roldán-Ruiz et al. (2000). For all accessions, PIC values ranged from 0.13 (PgSSR53) to 0.76 (PgSSR51), with an average of 0.42 (Table 4).

The NTSYSpc software calculated the genetic distances among ginseng cultivars. The eight cultivars were divided into three groups: I, II, and III (Fig. 1). The six Korean ginseng cultivars were divided into two groups. Group I contained Chunpoong, Yunpoong, Gopoong, and Jakyung. Group II contained two cultivars, Gumpoong and Hwangsook. Group III contained $P$. quinquefolius and $P$. notoginseng.

\section{DISCUSSION}

$P$. ginseng is one of the most important medicinal plants in Korea. Several cultivars that have different characteristics have been developed. For instance, Yunpoong is a cultivar that produces a higher yield than other cultivars and Chunpoong has good root shape and is suitable for red ginseng production (Lee 2002). Thus, molecular markers

Table 4. Characteristics of 8 SSR markers including GenBank accession, repeat motif, primer sequence, allele size range, number of alleles, genetic diversity, heterozygosity, and PIC among 8 cultivars of Panax species*.

\begin{tabular}{|c|c|c|c|c|c|c|c|c|}
\hline $\begin{array}{l}\text { Marker } \\
\text { ID }\end{array}$ & $\begin{array}{l}\text { GenBank } \\
\text { accession }\end{array}$ & Repeat motif & Forward primer $\left(5^{\prime} \rightarrow 3^{\prime}\right)$ & $\begin{array}{c}\text { Allele } \\
\text { size range } \\
\text { (bp) }\end{array}$ & $\begin{array}{l}\text { No. of } \\
\text { allele }\end{array}$ & $\begin{array}{l}\text { Genetic } \\
\text { diversity } \\
\text { (h) }\end{array}$ & $\begin{array}{l}\text { Hetero- } \\
\text { zygosity }\end{array}$ & PIC \\
\hline PgSSR07 & GU565701 & $(\mathrm{GAA})_{18}$ & $\begin{array}{l}\text { VIC-ATGGAAGTGGTTTGTGTTGG } \\
\text { AGGAGACCATGAAGGATTCG }\end{array}$ & $204-276$ & 3 & 0.34 & 0.26 & 0.32 \\
\hline PgSSR08 & EF531909 & $\left(\mathrm{GAAA}_{6}\right.$ & $\begin{array}{l}\text { NED-CCTGCTGGAGATTGAAGTCAT } \\
\text { GTTGGAATGCTTCAGCAGAT }\end{array}$ & $180-207$ & 5 & 0.61 & 0.59 & 0.55 \\
\hline PgSSR09 & GU565702 & $(\mathrm{AG})_{13}$ & $\begin{array}{l}\text { FAM-TGGATGATTTCGACATTTCTG } \\
\text { CCGTTCAACTAACCCCAAAC }\end{array}$ & $164-204$ & 3 & 0.51 & 0.59 & 0.42 \\
\hline PgSSR17 & BZ957342 & $(\mathrm{GGAACC})_{3}$ & $\begin{array}{l}\text { PET-ATCAGAACCGGAACTGGAAC } \\
\text { CTGAATTACCGAACCGAACC }\end{array}$ & $103-118$ & 3 & 0.21 & 0.08 & 0.20 \\
\hline PgSSR37 & EF140892 & $(\mathrm{ATG})_{7}(\mathrm{CTGATG})_{2}$ & $\begin{array}{l}\text { FAM-AATCAGAAACAAAGAAAGCTAAAAC } \\
\text { СТCTCTCATCTCTCTCTCTTCC }\end{array}$ & $100-122$ & 5 & 0.73 & 0.36 & 0.69 \\
\hline PgSSR40 & EF140893 & $(\mathrm{ATAG})_{2}$ & $\begin{array}{l}\text { VIC-GTAGTAGTAGTAAAACTTTGCTAACG } \\
\text { ATTTACAACTCTCTTCTTCCTCTAC }\end{array}$ & $125-162$ & 3 & 0.32 & 0.28 & 0.28 \\
\hline PgSSR51 & EF140899 & $(\mathrm{AAG})_{9}$ & $\begin{array}{l}\text { NED-GGAGGTGATTGATGTAGTGGAATCC } \\
\text { GGCTCTCCTATACTCACTATTTCCC }\end{array}$ & $299-330$ & 8 & 0.78 & 0.34 & 0.76 \\
\hline PgSSR53 & EF140900 & $(\mathrm{CTCCTTT})_{4}$ & $\begin{array}{l}\text { PET-CTACACGCTTTTTCATAGCTTACA } \\
\text { TGTCTGCATAAAAGAGTTCGAGGC }\end{array}$ & $185-194$ & 3 & 0.13 & 0.07 & 0.13 \\
\hline Average & & & & & 4.13 & 0.45 & 0.32 & 0.42 \\
\hline
\end{tabular}

*SSR: simple sequence repeat, PIC: polymorphic information content. 


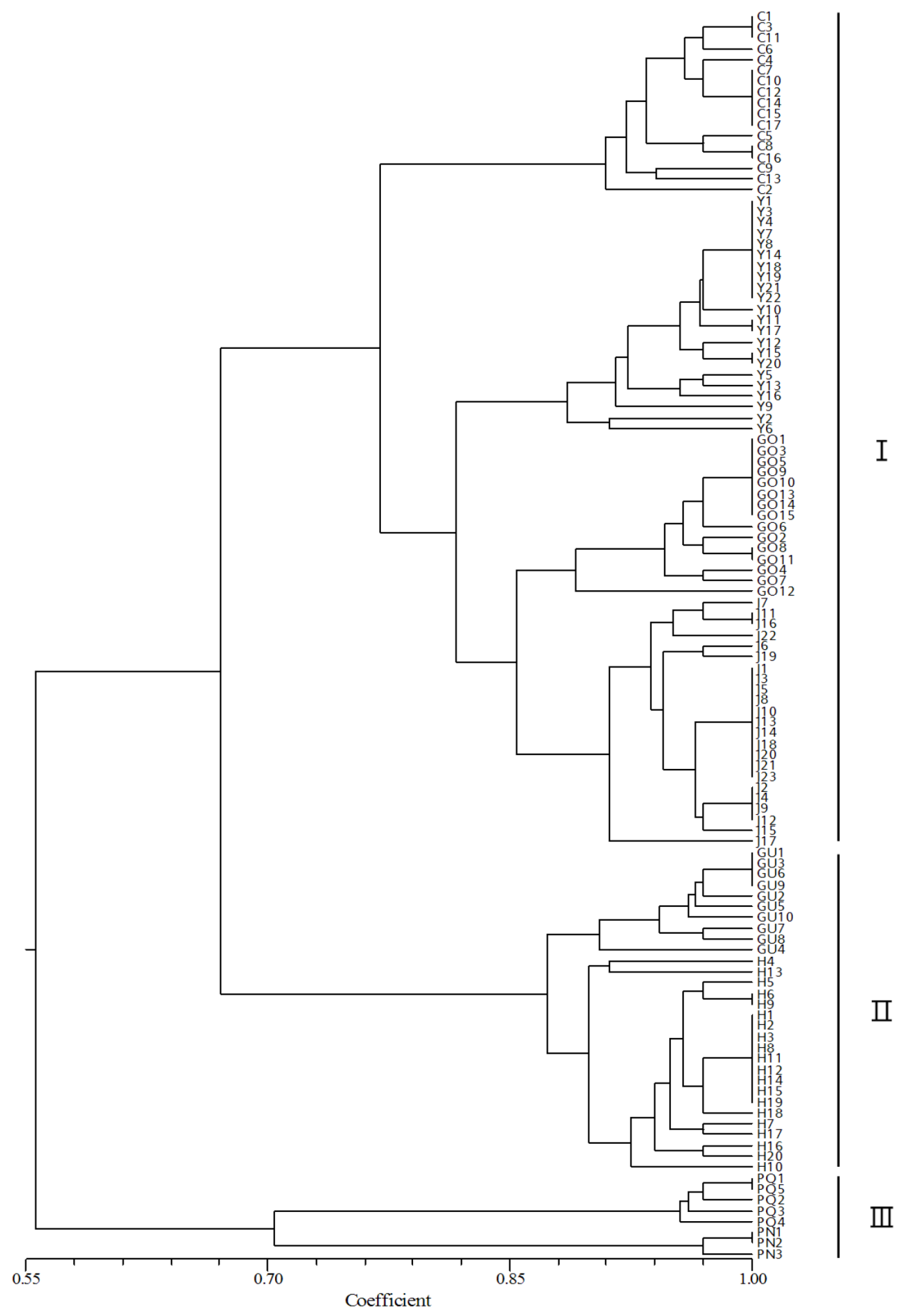

Fig. 1. Dendrograms showing genetic similarities among eight cultivars of ginseng, constructed using the Panax ginseng cultivars and Panax species similarity coefficient based on eight SSR markers (unweighted pair group method with arithmetic mean algorithm). Cultivars in Chunpoong (C), Yunpoong (Y), Gopoong (GO), Gumpoong (GU), Jakyung (J), Hwangsook (H), P. quinquefolius (PQ), P. notoginseng (PN). Group I contained C, Y, GO, and J. Group II contained GU and H. Group III contained P. quinquefolius and P. notoginseng. 
are needed to identify the cultivars for optimum utilization and further breeding. Previous researchers have developed various molecular markers-RAPD (Um et al. 2001; Cui et al. 2003; Shim et al. 2003; Lim et al. 2007), RFLP (Yang and Kim 2003), AFLP (Ha et al. 2002; Choi et al. 2008), STS (Bang et al. 2010), and SSR (Bang et al. 2011a, 2011b) - for identification of ginseng cultivars. But, it was not sufficient to identify all the Korean ginseng cultivars.

In this study, we collected 3,773 P. ginseng sequences from GSS and MEL databases. The selected primer sets were labeled with fluorescence at the 5 ' end of the forward primer for DNA fragment analysis. The DNA fragment analysis method with different fluorescent colors made it easy to analyze the genetic diversity. Especially for the similar-sized PCR products, labeling using different colors made it possible to analyze several markers at the same time. This method is cost- and time-effective for largesized samples. We used four colors of fluorescent dyes, FAM, NED, PET, and VIC. The product size of PgSSR09 and PgSSR17 was very similar, but it was possible to identify the markers because we used different colored dyes for each marker. Korean ginseng cultivars have very similar genotypes, therefore many markers are needed to differentiate the cultivars. Thus, we performed genotyping using eight SSR markers and DNA fragment analysis.

A dendrogram was constructed using the DNA fragment analysis data. The correlation coefficients between the cultivars were calculated from the genetic distance matrices based on PgSSR07, PgSSR08, PgSSR09, PgSSR17, PgSSR37, PgSSR40, PgSSR51, and PgSSR53 alleles. The correlation coefficients within the I, II, and III groups were $0.77,0.87$, and 0.70 , respectively. The correlation coefficients between groups I+II and III was estimated as 0.56 and the coefficient between groups I and II was 0.67. The low correlation coefficiency of the third combination indicates that alleles could come from all of the three genomes instead of only one or two genomes, so that genetic relationships between varieties can be accurately evaluated (Zhang et al. 2002).

Korean ginseng cultivars grouped together. Jakyung and Hwangsook have been cultivated as domestic varieties in Korea for a long time. Chunpoong, Yunpoong, and Gopoong were developed from Jakyung by selective breeding and Gumpoong was developed from Hwangsook by selective breeding. From the results, Chunpoong, Yunpoong, and Gopoong were grouped with Jakyung; and Gumpoong was grouped with Hwangsook. Therefore, dendrogram results are consistent with the history of Korean ginseng cultivars and Panax species. The traditional ginseng classification was based on morphology, so we generated molecular data to establish the Panax species lineage. Some researchers have published molecular markers for the identification of Panax species (Choi et al. 2011; Bang et al. 2012). But there is no report on the DNA fragment analysis method. For this reason, this study provides a very efficient method for classification study and shows the results of marker application using molecular markers in Panax species.

Consequently, our result is a case study demonstrating that SSR markers developed from GSS and MEL sequences of $P$. ginseng could be used for genetic studies in Panax species and Korean ginseng cultivars. These markers could be used for further research on cultivar development with molecular breeding techniques and conservation of the genetic diversity of the species in the genus. Moreover, the markers could be useful for genetic mapping and eventual marker-assisted selection in the crop. The use of next-generation sequencing will enable more rapid and efficient development of SSR markers.

\section{ACKNOWLEDGEMENTS}

This work was carried out with the support of "Cooperative Research Program for Agriculture Science \& Technology Development (Project No. PJ01102202)", Rural Development Administration, Republic of Korea.

\section{REFERENCES}

Ahn CH, Kim BB, Yoon ES, Choi YE. 2009. Development of microsatellite markers to distinguish south Korean and Chinese ginseng. J. Korean Forest Sci. 98: 568-575.

Bai H, Wang S, Liu J, Gao D, Jiang Y, Liu H, et al. 2015. Localization of ginsenosides in Panax ginseng with 
different age by matrix-assisted laser-desorption/ ionization time-of-flight mass spectrometry imaging. J. Chromatogr. B Analyt. Technol. Biomed. Life Sci. doi: 10.1016/j.jchromb.2015.09.024. [Epub ahead of print]

Bang KH, Lee JW, Kim YC, Kim DH, Lee EH, Jeung JU. 2010. Construction of genomic DNA library of Korean ginseng (Panax ginseng C. A. MEYER) and development of sequence-tagged sites. Biol. Pharm. Bull. 33: 15791588.

Bang KH, Chung JW, Kim YC, Lee JW, Jo IH, Seo AY, et al. 2011a. Development of SSR markers for identification of Korean ginseng (Panax ginseng C. A. Meyer.) cultivars. Korean J. Med. Crop Sci. 19: 185-190.

Bang KH, Jo IH, Chung JW, Kim YC, Lee JW, Seo AY, et al. 2011b. Analysis of genetic polymorphism of Korean ginseng cultivars and foreign accessions using SSR markers. Korean J. Med. Crop Sci. 19: 347-353.

Bang KH, Seo AY, Chung JW, Kim YC, Jo IH, Kim JU, et al. 2012. Analysis of genetic polymorphism and relationship of Korean ginseng cultivars and breeding lines using EST-SSR marker. Korean J. Med. Crop Sci. 20: 277-285.

Choi HI, Kim NH, Kim JH, Choi BS, Ahn IO, Lee JS, et al. 2011. Development of reproducible EST-derived SSR markers and assessment of genetic diversity in Panax ginseng cultivars and related species. J. Ginseng Res. 35: 399-412.

Choi YE, Ahn CH, Kim BB, Yoon ES. 2008. Development of species specific AFLP-derived SCAR marker for authentication of Panax japonicus C.A. MEYER. Biol. Pharm. Bull. 31: 135-138.

Cui XM, Lo CK, Yip KL, Dong TT, Tsim KW. 2003. Authentication of Panax notoginseng by 5S-rRNA spacer domain and random amplified polymorphic DNA (RAPD) analysis. Planta Med. 69: 584-586.

Ha WY, Shaw PC, Liu J, Yau FC, Wang J. 2002. Authentication of Panax ginseng and Panax quinquefolius using amplified fragment length polymorphism (AFLP) and directed amplification of minisatellite region DNA (DAMD). J. Agric. Food Chem. 50: 1871-1875.

Hon CC, Chow YC, Zeng FY, Leung FC. 2003. Genetic authentication of ginseng and other traditional Chinese medicine. Acta Pharmacol. Sin. 24: 841-846.

Jee HS, Chang KH, Park SH, Kim KT, Paik HD. 2014. Morphological characterization, chemical components, and biofunctional activities of Panax ginseng, Panax quinquefolium, and Panax notoginseng roots: A comparative study. Food Rev. Int. 30: 91-111.

Jo BH, Suh DS, Cho EM, Kim JK, Ryu GH, Chung KW. 2009. Characterization of polymorphic microsatellite loci in cultivated and wild Panax ginseng. Genes Genom. 31: 119-127.

Jo IH, Bang KH, Kim YC, Kim JU, Shin MR, Moon JY, et al. 2013. Analysis of mitochondrial DNA sequence and molecular marker development for identification of Panax species. Korean J. Med. Crop Sci. 21: 91-96.

Kim J, Jo BH, Lee KL, Yoon ES, Ryu GH, Chung KW. 2007. Identification of new microsatellite markers in Panax ginseng. Mol. Cells 24: 60-68.

Kim YJ, Jang MG, Zhu L, Silva J, Zhu X, Sukweenadhi J, et al. 2015. Cytological characterization of anther development in Panax ginseng Meyer. Protoplasma. doi: 10.1007/ s00709-015-0869-3. [Epub ahead of print]

Koressaar T, Remm M. 2007. Enhancements and modifications of primer design program Primer3. Bioinformatics 23: 1289-1291.

Lee MJ, Kim EH, Rhee DK. 2008. Effect of Panax ginseng on stress. J. Ginseng Res. 32: 8-14.

Lee SS. 2002. Characteristics of photosynthesis among new cultivars of ginseng (Panax ginseng C.A. Meyer). J. Ginseng Res. 26: 85-88.

Lim W, Mudge KW, Weston LA. 2007. Utilization of RAPD markers to assess genetic diversity of wild populations of North American ginseng (Panax quinquefolium). Planta Med. 73: 71-76.

Lim YP, Choi KT. 1990. The characterization of mitochondrial DNA of Korean ginseng (Panax ginseng C.A. Meyer). Korean J. Ginseng Sci. 14: 310-316.

Lim YP, Shin CS, Lee SJ, Youn YN, Jo JS. 1993. Survey of proper primer and genetic analysis of Korean ginseng (Panax ginseng C.A. Meyer) variants using the RAPD technique. Korean J. Ginseng Sci. 17: 153-158.

Liu K, Muse SV. 2005. PowerMarker: An integrated analysis environment for genetic marker analysis. Bioinformatics 21: 2128-2129.

Ma KH, Dixit A, Kim YC, Lee DY, Kim TS, Cho EG, et al. 2007. Development and characterization of new microsatellite markers for ginseng (Panax ginseng C. A. Meyer). Conserv. Genet. 8: 1507-1509.

Mogea JP. 1999. Relationships and phylogeny of the species 
of the genus Arenga (Palmae) based on morphology using the polarity method and the NTSYS program. Mem. New York Bot. Gard. 83: 169-177.

Nam MH, Kim SI, Liu JR, Yang DC, Lim YP, Kwon KH, et al. 2005. Proteomic analysis of Korean ginseng (Panax ginseng C.A. Meyer). J. Chromatogr. B Analyt. Technol. Biomed. Life Sci. 815: 147-155.

Nguyen VD, Nirala R, Choi SR, Uhm TS, Yang TJ, Ahn IO, et al. 2010. Development and characterization of new microsatellite markers in Panax ginseng C. A. Meyer from BAC end sequences. Conserv. Genet. 11: 1223-1225.

Park SW, Hyun YS, Chung KW. 2009. Genetic polymorphism of microsatellite in Panax ginseng C.A. Meyer. J. Ginseng Res. 33: 199-205.

Powell W, Machray GC, Provan J. 1996. Polymorphism revealed by simple sequence repeats. Trends Plant Sci. 1: 215-222.

Roldán-Ruiz I, Dendauw J, Van Bockstaele E, Depicker A, De Loose M. 2000. AFLP markers reveal high polymorphic rates in ryegrasses (Lolium spp.). Mol. Breed. 6: 125-134.

Sharma SK, Pandit MK. 2009. A new species of Panax L. (Araliaceae) from Sikkim Himalaya, India. Syst. Bot. 34: 434-438.

Shim YH, Choi JH, Park CD, Lim CJ, Cho JH, Kim HJ. 2003. Molecular differentiation of Panax species by RAPD analysis. Arch. Pharm. Res. 26: 601-605.

Silva PI, Martins AM, Gouvea EG, Pessoa-Filho M, Ferreira ME. 2013. Development and validation of microsatellite markers for Brachiaria ruziziensis obtained by partial genome assembly of Illumina single-end reads. BMC Genomics 14: 17.

Untergasser A, Cutcutache I, Koressaar T, Ye J, Faircloth BC, Remm M, et al. 2012. Primer3: new capabilities and interfaces. Nucleic Acids Res. 40: e115.

Um JY, Chung HS, Kim MS, Na HJ, Kwon HJ, Kim JJ, et al. 2001. Molecular authentication of Panax ginseng species by RAPD analysis and PCR-RFLP. Biol. Pharm. Bull. 24: 872-875.

Woo SY, Lee DS, Kim PG. 2004. Growth and ecophysiological characteristics of Panax ginseng grown under three different forest type. J. Plant Biol. 47: 230-235.

Yang DC, Kim MS. 2003. DNA analysis of ginseng using PCR-aided RFLP technology. J. Ginseng Res. 27: 146-150.

Yu RH, Zhao YJ, Xu KZ, Zhang MS, Zhang ZA, Chen ZY. 2009. Diurnal changes of photosynthesis in Panax ginseng and Panax quinquefolium under different environmental conditions. J. South China Agr. Univ. 30: 7-11.

Zhang XY, Li CW, Wang LF, Wang HM, You GX, Dong YS. 2002. An estimation of the minimum number of SSR alleles needed to reveal genetic relationships in wheat varieties. I. Information from large-scale planted varieties and cornerstone breeding parents in Chinese wheat improvement and production. Theor. Appl. Genet. 106: 112-117. 